\title{
Controle de obras por RFID: sistema de monitoramento e controle para equipamentos de segurança no canteiro de obras
}

\author{
Controlling work using RFID: monitoring and control \\ system for safety equipment at construction sites
}

\section{Victor Hugo Mazon de Oliveira Sheyla Mara Baptista Serra}

\begin{abstract}
Resumo
$\mathbf{E}$ relevante o papel da Tecnologia da Informação e Comunicação (TIC) aplicada à cadeia produtiva da construção, em particular na gestão de equipamentos de segurança, cujas práticas convencionais de controle têm mostrado eficiência limitada. Sendo assim, este trabalho apresenta o estudo do desenvolvimento de um sistema de monitoramento e controle remoto de equipamentos de segurança utilizando a tecnologia Radio Frequency Identification (RFID) administrado pelo software, também desenvolvido nesta pesquisa, intitulado Controle de Obras por RFID. A rotina de ensaios combinou testes de laboratório para hospedagem e validação do sistema e experimentos em um canteiro de obras para a verificação do sistema em um ambiente real de construção. O modelo mostrou-se eficiente na identificação e localização dos equipamentos por meio da indicação de sua posição em imagens em planta. $\mathrm{O}$ modelo forneceu também relatórios gráficos e textuais que exibem as características de cada equipamento e apresentam os seguintes dados: nome, obra, local, marca, material, estado de conservação, previsão de revisão e responsável. A introdução da TIC no desenvolvimento de ferramentas, como o sistema proposto por este estudo, contribui para o avanço da gestão de equipamentos de segurança no canteiro de obras, podendo ser extrapolado para a gestão de outros componentes.
\end{abstract}

Palavras-chave: Tecnologia da Informação e Comunicação (TIC). Radio Frequency Identification (RFID). Equipamentos de proteção coletiva. Canteiro de obras.

\begin{abstract}
Information and Communication Technology (ICT) applied to the construction supply chain plays an important role, particularly when managing security equipment, whose conventional control practices have shown limited efficiency. Therefore, the aim of this study is to develop a monitoring and control system for the remote monitoring of security equipment using Radio Frequency Identification (RFID) technology administered by software, which was also developed in this research called: Controlling work using RFID. The testing routine combined laboratory testing for hosting and system validation and testing at a construction site for system verification in a real building environment. The model proved to be efficient in terms of identifying and locating equipment by indicating its position in plant images. The model also provided graphical reports showing the characteristics of each piece of equipment presenting the following data: name, construction, location, brand, material, state of conservation, review forecast and person in charge. The introduction of ICT to develop tools, such as the system proposed in this study, helps advance the intelligent management of safety equipment at construction sites.
\end{abstract}

Sheyla Mara Baptista Serra Universidade Federal de São Carlos
São Carlos - SP - Brasil

Recebido em 22/03/17

Aceito em 25/07/17

Victor Hugo Mazon de Oliveira Federal de São Carlos São Carlos - SP - Brasil
Keywords: Information and Communication Technology (ICT). Radio Frequency

Identification (RFID). Collective security equipments. Construction site. 


\section{Introdução}

A indústria da construção civil necessita de melhorias contínuas em seus processos construtivos e gerenciais. Para isso, mudanças no pensamento estratégico e na elaboração de sistemas de gestão são necessários para conduzir o setor ao uso de novas tecnologias, métodos e procedimentos que possam proporcionar um ambiente integrado, seguro e de alta produtividade (THOMAZ, 2001).

A grande quantidade e diversidade dos recursos físicos envolvidos no processo de produção, como materiais, equipamentos e operários, gera a necessidade de criar procedimentos de gestão que sejam mais eficientes e transparentes para uso pelos gestores e tomadores de decisão na construção civil. O uso da Tecnologia de Informação e Comunicação (TIC) para rastreamento e coleta de informações colabora para que as decisões e o controle da produção sejam embasados em dados de acompanhamento reais.

Segundo o Ministério da Previdência Social (BRASIL, 2015a), entre os anos de 2006 e 2010, período em que o setor da construção civil teve grande expansão, com o consequente aumento no número de empregados, a quantidade de acidentes de trabalho aumentou de 29.054 para 54.664 , ou seja, um crescimento de $88,14 \%$. Portanto, torna-se necessário que sejam envidados esforços para reduzir os riscos de acidentes do trabalho, que permitam manter a produtividade e o bom ambiente de trabalho.

As especificidades e a diversidade das atividades realizadas nos canteiros de obra ampliam os riscos a que os trabalhadores estão expostos, sendo necessária a tomada de medidas preventivas. As normas regulamentadoras e as normas técnicas orientam para que várias medidas de prevenção ou redução dos acidentes do trabalho sejam tomadas. Entre elas se destaca a implantação dos equipamentos de proteção coletiva (EPC), que são definidos de acordo com as características das atividades em execução no momento da obra. Existem várias soluções tecnológicas disponíveis no mercado, e é possível o reaproveitamento dos EPC. Entretanto, nem sempre os EPC são instalados de forma eficiente ou são devidamente controlados durante seu uso. Normalmente, os EPC são montados e, após a execução de determinados serviços, são desmontados e remontados em outros pavimentos, o que pode gerar perdas e provocar erros durante a nova instalação.

Assim, torna-se importante desenvolver um processo de controle desses equipamentos que facilite a tomada de decisões e preserve a segurança em canteiro. Observa-se que podem ser desenvolvidos sistemas de apoio gerencial que controlem, por exemplo, a periodicidade de manutenção ou que verifiquem sua instalação no local conforme os projetos.

Considerando os riscos ao trabalhador presentes em qualquer atividade da construção e a grande quantidade e diversidade de EPC presentes no canteiro de obras, a utilização da TIC na concepção de novas ferramentas gerenciais reduz o tempo e os recursos despendidos com a operação de sistemas de segurança convencionais.

Para Demiralp, Guven e Ergen (2012), existem problemas nos métodos tradicionais de rastreamento e controle de materiais que resultam em entregas atrasadas, falta de componentes ou instalações e montagens incorretas. Para esses autores, o uso de tecnologias de coleta de dados, como Radio Frequency Identification (RFID), podem ajudar na gestão de componentes em cadeias de fornecimento de construção. $\mathrm{O}$ trabalho de Demiralp, Guven e Ergen (2012) apresenta um estudo de caso com painéis de parede pré-moldada de concreto. Nesse caso, o sistema de controle incluiu as atividades em uma planta de produção, como transporte, manejo dos elementos e atividades de montagem no canteiro de obras. O processo desenvolvido consistiu em que, depois que um painel ou componente foi produzido, os trabalhadores o marcassem com uma etiqueta, que é parte do sistema RFID usada para identificar os painéis. Com isso, foi possível rastrear e localizar painéis ao longo da cadeia de fornecimento e montagem. Dessa forma, verificou-se a aplicabilidade de um sistema RFID no rastreamento de materiais, componentes $\mathrm{e}$ equipamentos utilizados na construção civil.

Normalmente, identificar, rastrear e localizar equipamentos ao longo da cadeia produtiva da construção é um trabalho desafiador. Os métodos usuais são baseados em anotações manuais em papel. Os problemas encontrados nos métodos convencionais de monitoramento consistem no extravio de componentes, instalações incorretas, manutenção inadequada e falta de materiais, componentes e equipamentos. Conhecer a localização e as características dos produtos a serem monitorados, de forma dinâmica e em tempo real, é uma vantagem que pode ser adicionada a um modelo de gestão. Na construção, recursos consideráveis de tempo e esforço humano são gastos na tentativa de controlar os diversos produtos e serviços em desenvolvimento. No caso dos EPC, que são utilizados em grande quantidade, 
a utilização de um sistema de controle pode trazer, além da eficiência no processo, mais saúde e segurança ao ambiente de trabalho na construção.

Este trabalho, portanto, objetiva propor um sistema de controle e monitoramento de equipamentos de segurança utilizando a tecnologia RFID. O sistema destina-se a contribuir com a gestão dos equipamentos de segurança distribuídos na planta do edifício. Além disso, a rotulagem de cada componente proporcionará a identificação de suas características e informações técnicas (nome, obra, local, marca, material constituinte, estado de conservação, previsão da próxima revisão e responsável). Ao longo de sua operação, o sistema armazenará todas as informações registradas, formando um banco de dados e um histórico das atividades.

Para isso, um programa computacional foi desenvolvido especificamente para este trabalho, denominado Controle de Obras por RFID. A simulação da operação do programa buscou testar e validar os procedimentos e o funcionamento da ferramenta de gestão desenvolvida. As contribuições obtidas com este estudo incluem os resultados dos testes, uma avaliação do funcionamento do sistema desenvolvido utilizando a tecnologia RFID, o desenvolvimento de um novo software e recomendações para futuras pesquisas.

Como a tecnologia RFID ainda não é amplamente aplicada na indústria da construção civil, um objetivo secundário do trabalho foi a identificação das principais características do sistema a ser implantado, buscando revelar as vantagens e as dificuldades na operação da tecnologia.

Dessa forma, entende-se que a utilização do método de rastreamento remoto com identificação automática através de sinais de radiofrequência, recuperando e armazenando dados remotamente, tem função preventiva significativa, disponibilizando informações para o planejamento de processos construtivos, e contribui, ainda, no desenvolvimento de mecanismos voltados a proporcionar um ambiente de trabalho seguro.

\section{Tecnologia RFID na indústria da construção}

A tecnologia RFID considera a utilização de um dispositivo eletrônico via radiofrequência ou variação do campo magnético para a transmissão de dados (FINKENZELLER, 2010). O funcionamento detalhado do sistema é descrito por Domdouzis, Kumar e Anumba (2007), Maghiros, Rotter e Lieshout (2007) e Zhekun, Gadh e Prabhu (2004). Segundo todos esses autores, o sistema estrutural de identificação por radiofrequência típico inclui três componentes básicos: um leitor equipado com um transmissor com decodificador; um transponder configurado por uma etiqueta de radiofrequência (Tag) eletronicamente programada; e um software de controle. A Figura 1 ilustra os componentes de um sistema RFID. O leitor emite sinais de rádio continuamente em dada frequência. Quando uma Tag configurada para detectar a frequência de trabalho utilizada entra em contato com esses sinais, ela é ativada e se comunica com o leitor pela modulação de transmitância de frequências. O leitor obtém e analisa os dados e os envia ao sistema que está conectado para reconhecer os protocolos de comunicação em um computador.

O sistema de comunicação RFID pode ser classificado como ativo quando o equipamento é energizado por uma bateria, ou é classificado como passivo quando não há uso de baterias (REN; ANUMBA; TAH, 2011). As Tags passivas estão normalmente no estado "inativo" até serem ativadas pelo campo emitido pelo leitor. Nas Tags passivas o campo eletromagnético do leitor age para carregar o capacitor que alimenta a Tag. Devido à intensidade do sinal requerido, as Tags passivas são utilizadas mais frequentemente para aplicações em pequenas distâncias $(<1,5 \mathrm{~m}) \mathrm{e}$ exigem um leitor de alta potência com antena capaz de ler as informações transmitidas. As etiquetas passivas são leves, compactas e têm expectativa de vida ilimitada (MAGHIROS; ROTTER; LIESHOUT, 2007).

Figura 1 - Componentes do sistema RFID

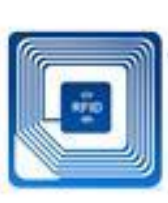

Etiqueta RFID

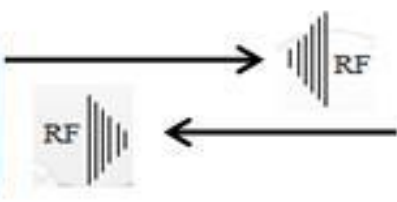

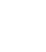

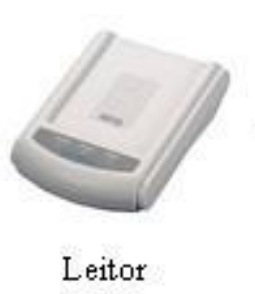

RFID

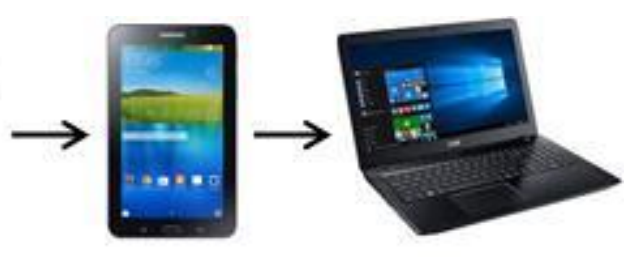

Tablet. de apoio
Computador 
As Tags ativas são normalmente alimentadas por uma bateria interna. Sua duração pode ser de anos, porém esse período está estritamente relacionado com sua aplicação. São utilizadas para aplicações de longo alcance, com leituras de até $100 \mathrm{~m}$. São capazes de emitir sinais continuamente e possibilitam a leitura e gravação de dados. Devido a esses aumentos de capacidade, as Tags ativas são mais pesadas, mais caras e têm expectativa de vida limitada (LIESHOUT et al., 2007; MEHRJERDI, 2008).

A principal vantagem do uso de sistemas RFID é permitir a leitura sem o contato ou visualização direta do leitor com a etiqueta, como no código de barras (SANGREMAN; CAMANHO, 2007). Ao contrário do uso do feixe de luz utilizado no sistema de código de barras, a tecnologia RFID utiliza ondas eletromagnéticas (sinais de rádio) para transmitir ou capturar dados armazenados num chip ou etiqueta.

Uma característica importante do leitor é sua capacidade para evitar colisões entre as frequências das etiquetas de RFID, por usar métodos específicos de separação. Ao utilizar métodos anticolisão, um leitor pode realizar múltiplas leituras, o que acelera o processo. A utilização de um sistema anticolisão eficiente é essencial para calcular a transmissão de dados e a taxa do processo de leitura em número de leituras por segundo (MAGHIROS; ROTTER; LIESHOUT, 2007).

Essa tecnologia pode ser aplicada em inúmeras áreas para fins de controle de almoxarifado, localização de materiais e pessoas, controle de entrada e saída de produtos, veículos e pessoas, identificação de ferramentas ou animais, entre outros.

$\mathrm{Na}$ indústria da construção, as empresas têm se interessado em introduzir soluções utilizando a tecnologia RFID em sua cadeia produtiva. No entanto, mesmo diante das demandas do mercado, ainda há um longo caminho antes que a tecnologia possa ser implantada em toda a indústria, principalmente devido ao desconhecimento de seu potencial de uso.

Os exemplos de aplicação do sistema RFID na indústria da construção são identificados em diferentes situações.

Song et al. (2005) apresentaram um método de aplicação de RFID nos canteiros de obras para determinar a localização exata de materiais marcados. Os testes de campo indicaram que a tecnologia poderia funcionar de forma eficaz no ambiente de área de construção, envolvendo objetos metálicos grandes que exigiam leitura de longo alcance. Os benefícios percebidos no rastreamento automatizado foram: redução do tempo de identificação e localização de materiais após a recepção e antes do envio; precisão das informações sobre o transporte, recebimento e estoque; redução do tempo para procurar materiais perdidos; e aumento da confiabilidade no cronograma de montagem.

Giretti et al. (2009) realizaram um experimento dedicado à gestão da segurança e saúde em canteiros de obras com o uso de novas tecnologias de comunicação, alimentadas por sistema de identificação por RFID. O sistema implantado emitia sinais de aviso de perigo quando o trabalhador se aproximava da região com maior risco de acidente. Assim, a função inicial do sistema RFID consistiu em identificar em tempo real o rastreamento da posição dos trabalhadores envolvidos em atividades da construção civil e, para isso, foi desenvolvido de um software capaz de controlar o acesso não autorizado às zonas perigosas.

Costin, Pradhananga e Teizer (2012) acompanharam por vários meses consecutivos a implantação do sistema RFID em um edifício com mais de 50 trabalhadores da construção civil, várias formas de transporte de componentes e materiais, e itens de trabalho relacionados, como elevadores de materiais. Uma das vantagens do sistema implantado foi a produção de um banco de dados com variedade de opções para a análise de dados. A automatização da coleta e análise de dados economizou tempo significativo dos gestores, o que apoiou a tomada de decisões.

Em outra situação, Wu et al. (2013), com base nos resultados de um estudo de caso, argumentam que, de um total de 499 casos de acidentes de trabalho devido à queda de objetos, 66\% (330 casos) dos acidentes tinham o potencial de ser evitados de forma proativa e preventiva. Os autores apresentam o desenvolvimento de um sistema proativo de prevenção de acidentes causados por objetos caídos visando à identificação em tempo real e ao rastreamento de localização de objetos para promover melhorias e correções. Como exemplo de fixação das etiquetas de identificação dos objetos caídos, podem ser citados componentes de andaimes, de plataformas de trabalho ou de periferia, entre outros.

Uma das aplicações em operação é descrita pelo RFID Journal Brasil (2015). A implantação do sistema RFID tem o intuito de monitorar se os colaboradores de uma empresa do setor elétrico estão utilizando adequadamente todos os equipamentos de proteção individual (EPI) necessários para realizar os serviços de campo. 
Genericamente, instala-se no colete um leitor RFID com duas baterias, um módulo de leitura RFID e três antenas integradas para a leitura de todas as áreas do corpo de cada trabalhador. Além disso, há um leitor portátil que funciona anexado a um smartphone e que atua como um leitor RFID móvel para a leitura dos EPI e dos EPC que são carregados nos carros de serviço da empresa e dos terceirizados.

Assim, observa-se um grande potencial para aplicação do RFID na construção, especialmente na área de gestão da segurança do trabalho. Para Riaz, Edwards e Thorpe (2006), a combinação das tecnologias avançadas (como Global Positioning System (GPS), redes de sensores inteligentes e comunicação sem fios) pode ser utilizada numa estratégia proativa de desenvolvimento do sistema de gestão da segurança e saúde dos trabalhadores.

\section{Sistemas de proteção coletiva na indústria da construção civil}

Como forma de reduzir os acidentes de trabalho, podem ser propostas barreiras físicas que evitem o contato do trabalhador com o agente causador do acidente. Hollnagel (2004) define equipamentos de proteção coletiva (EPC) como barreiras físicas ou funcionais destinadas à prevenção de acidentes e não incorporadas ao corpo ou vestimenta dos operários.

De maneira geral, os EPC, também denominados de sistema de proteção coletiva (SPC), fazem parte de um sistema integrado que considera o conjunto de dispositivos de proteção que abrangem o maior número de indivíduos no ambiente de trabalho, ou seja, são dispositivos que protegem os indivíduos ocupantes de determinado ambiente laboral.

Entre os SPC usualmente empregados contra os riscos de queda em altura nos canteiros de obra estão os sistemas de guarda-corpos rodapé (GcR) e sistemas de plataforma de proteção coletiva (bandejas), conforme a Figura 2.

Com relação à segurança, conforme estabelecido pela Norma Regulamentadora 18 (NR-18) no item 18.3.1, "É obrigatória a instalação de proteção coletiva onde houver risco de queda de trabalhadores ou de projeção de materiais" (BRASIL, 2015b). Nesse sentido, estes sistemas GcR e plataforma - se caracterizam como elementos de proteção do tipo barreira contra queda efetiva de trabalhadores ou materiais. Eles, entretanto, não têm caráter preventivo, ou seja, não são capazes de alertar o sujeito quanto ao perigo eminente.

\section{Figura 2 - SPC contra quedas em altura}
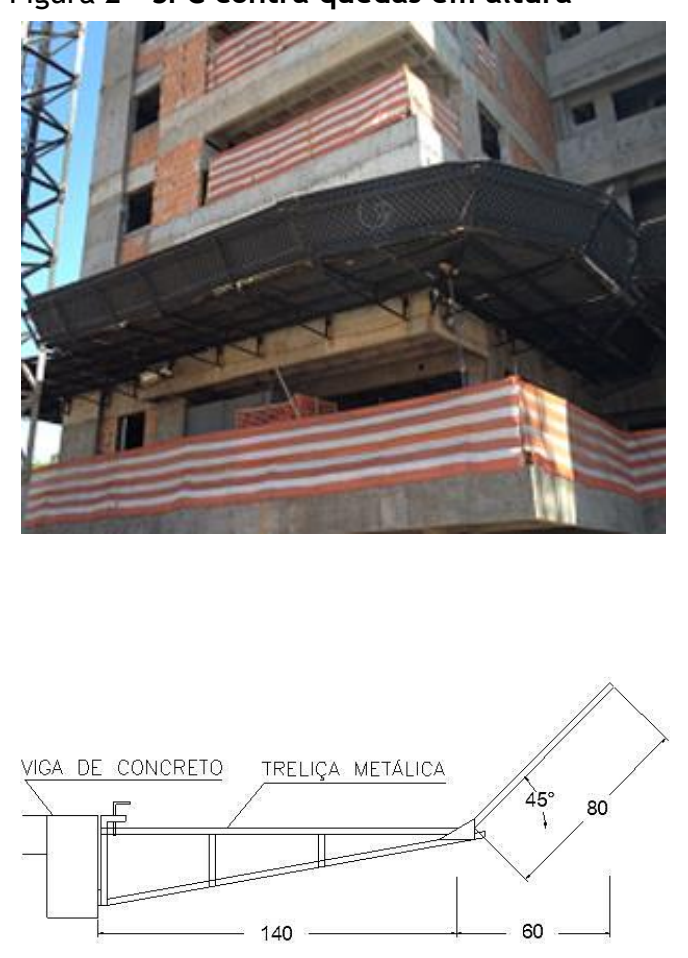
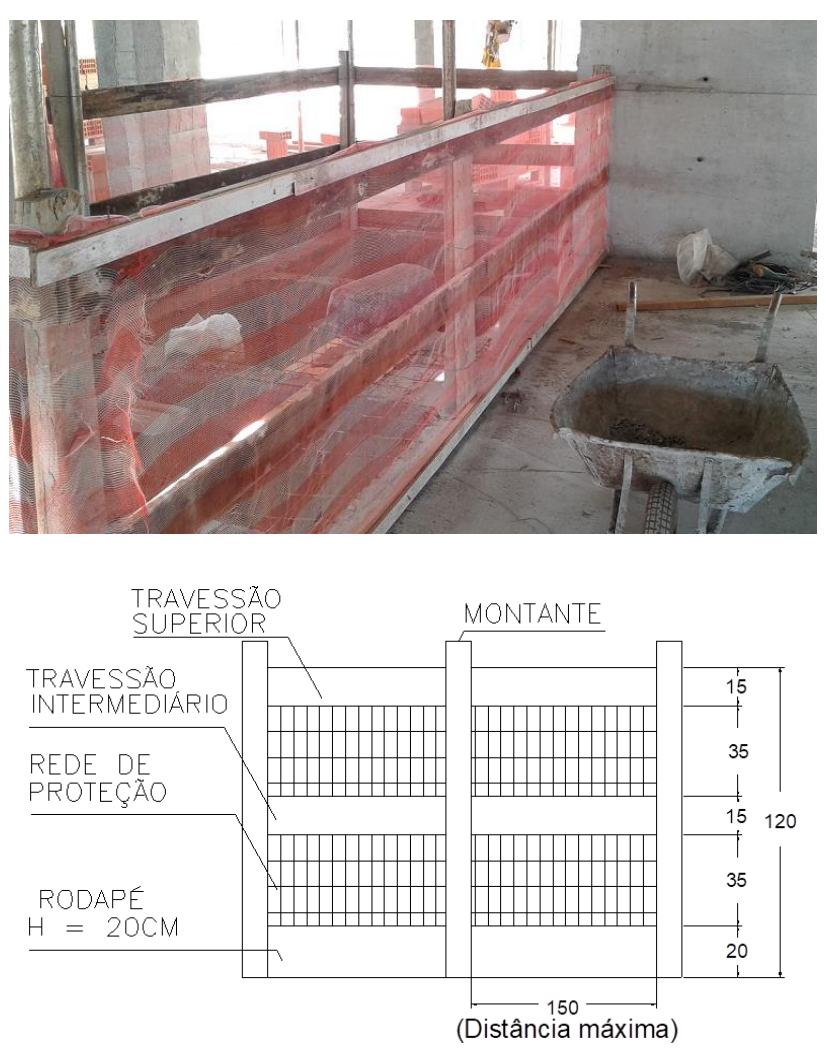
A fixação dos SPC ocorre normalmente perto da periferia dos pavimentos e em condições de trabalho com risco de quedas em altura. A quantidade de peças existentes num sistema de bandeja secundário depende do perímetro do edifício e pode ser significativa - mais de 100 peças para ser controladas. Essas estruturas são montadas a cada 3 lajes dos edifícios com múltiplos pavimentos, podendo ser necessário mais de um jogo de bandeja por torre. Após o fechamento da alvenaria nos pavimentos superiores as bandejas são desmontadas, transportadas e remontadas em novas lajes. Assim, torna-se importante desenvolver mecanismos de gerenciamento desses equipamentos de forma a ser possível a reutilização deles com segurança.

No sistema convencional utilizado na gestão dos EPC, o controle das movimentações e entradas e saídas dos equipamentos no canteiro ocorrem manualmente, através dos apontamentos realizados pelo almoxarife. Entretanto, na prática, as movimentações e transferências dos equipamentos são realizadas acompanhando a sequência executiva das atividades da obra com base em suas necessidades e sem o acompanhamento do almoxarife. A falta de controle e monitoramento no curso dessas atividades resulta, por exemplo, no extravio de peças, no desconhecimento do estado de conservação dos equipamentos, na subutilização ou no abandono dos componentes.

Dados os riscos inerentes ao processo de montagem e desmontagem desses SPC, torna-se necessário o estudo e desenvolvimento de um sistema preventivo contra o risco de queda usando a Tecnologia da Informação (TI) como instrumento.

\section{Método de desenvolvimento da pesquisa}

Kauark, Manhães e Medeiros (2010) indicam que distinguir o tipo de pesquisa a ser empregado é necessário para a definição dos instrumentos e procedimentos que um pesquisador precisa utilizar no planejamento de sua investigação. Fontelles et al. (2009) complementam ao caracterizar a pesquisa como a aplicação prática de um conjunto de procedimentos objetivos, utilizados por um pesquisador para o desenvolvimento de um experimento a fim de produzir um novo conhecimento, além de integrá-lo àqueles preexistentes. Uma abordagem de pesquisa aplicada, segundo Gerhardt e Silveira (2009), gera conhecimentos para aplicação prática, dirigidos à solução de problemas específicos. É também o tipo de pesquisa que, além de produzir conhecimento, gera novos processos tecnológicos e novos produtos, com resultados práticos imediatos, como o proposto neste trabalho.

A metodologia de pesquisa adotada para este estudo foi a Design Science Research (DSR). Segundo Hevner et al. (2004), é uma metodologia que operacionaliza e fundamenta a condução da pesquisa quando o objetivo a ser alcançado é um artefato, ou seja, o principal meio pelo qual se pode gerar novos conhecimentos baseados em experiências práticas. Nesse sentido, a DSR se coloca como um processo rigoroso de projetar artefatos para resolver problemas, avaliar o que foi projetado ou o que está funcionando e comunicar os resultados obtidos.

A definição da metodologia para esta pesquisa considerou uma característica fundamental da DSR como método. Segundo Van Aken (2004), essa metodologia é orientada para a solução de problemas específicos, não necessariamente buscando soluções definitivas, mas, sim, soluções satisfatórias para a situação em questão. No entanto, as soluções geradas devem ser passíveis de generalização para determinada classe de problemas. Essa generalização deve permitir que outros pesquisadores e profissionais, em situações diversas, também possam fazer uso do conhecimento gerado.

Uma das principais razões para a aplicação da DSR neste estudo foi a possibilidade de superar a lacuna existente sobre a tecnologia RFID e sua aplicação específica no monitoramento e gestão de equipamentos em áreas de risco de queda em canteiros de obra. Para Van Aken (2004), isso ocorre porque é um método orientado à solução de problemas e que, ao mesmo tempo, produz conhecimento que pode servir de referência para o aprimoramento de teorias. A Figura 3 mostra a estrutura conceitual de compreensão, execução e avaliação na investigação de sistemas de informação proposta por Hevner et al. (2004) adaptada à proposta deste estudo.

A investigação proposta abrange, portanto, o desenvolvimento de um sistema de controle e monitoramento que integre a tecnologia RFID e a determinação de sua funcionalidade em função da necessidade de gestão dos EPC.

Para a identificação dos equipamentos de segurança foi utilizada a Tag passiva de modelo B20070/C-20055, resistente à interferência de estruturas metálicas e intempéries sobre o funcionamento de sua transmissão de dados (Quadro 1). Esse modelo passivo não é dotado de fonte de energia próprio, suas funções são ativadas quando a Tag ingressa no campo de trabalho do leitor e inicia-se a comunicação por ondas eletromagnéticas (MAGHIROS; ROTTER; 
LIESHOUT, 2007). Para o reconhecimento das Tags foi utilizado o leitor RFID móvel de modelo UHF 900 BT (Quadro 1). Este é um equipamento leve, de grande mobilidade, que opera na faixa de frequência entre 800 e $960 \mathrm{MHz}$. O acesso a seu banco de dados interno pode ser feito via bluetooth ou cabo de transmissão de dados.

Figura 3 - Estrutura de investigação utilizando a DSR para a aplicação da tecnologia RFID deste estudo

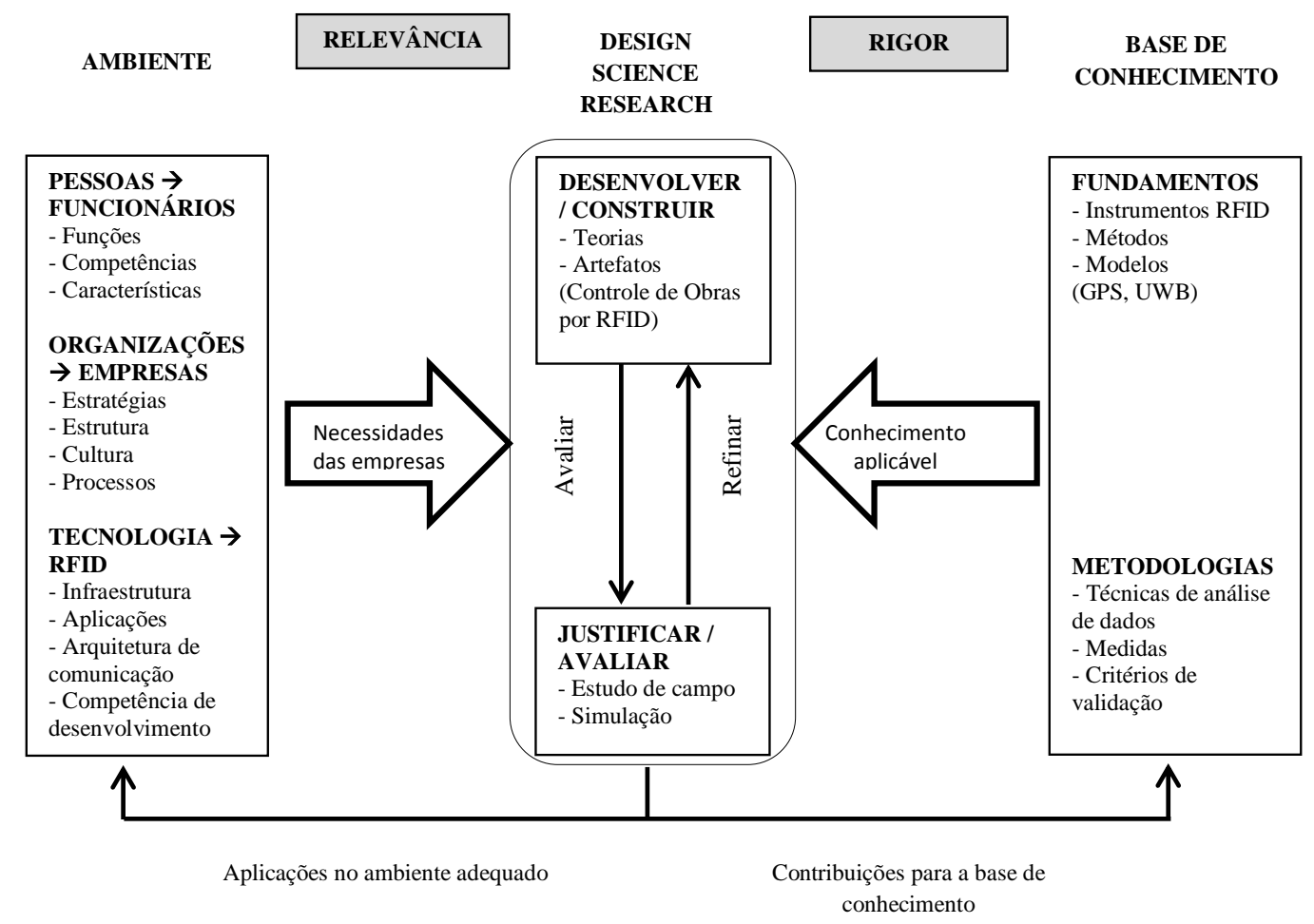

Fonte: adaptado de Hevner et al. (2004).

Quadro 1 - Equipamentos RFID utilizados nos testes

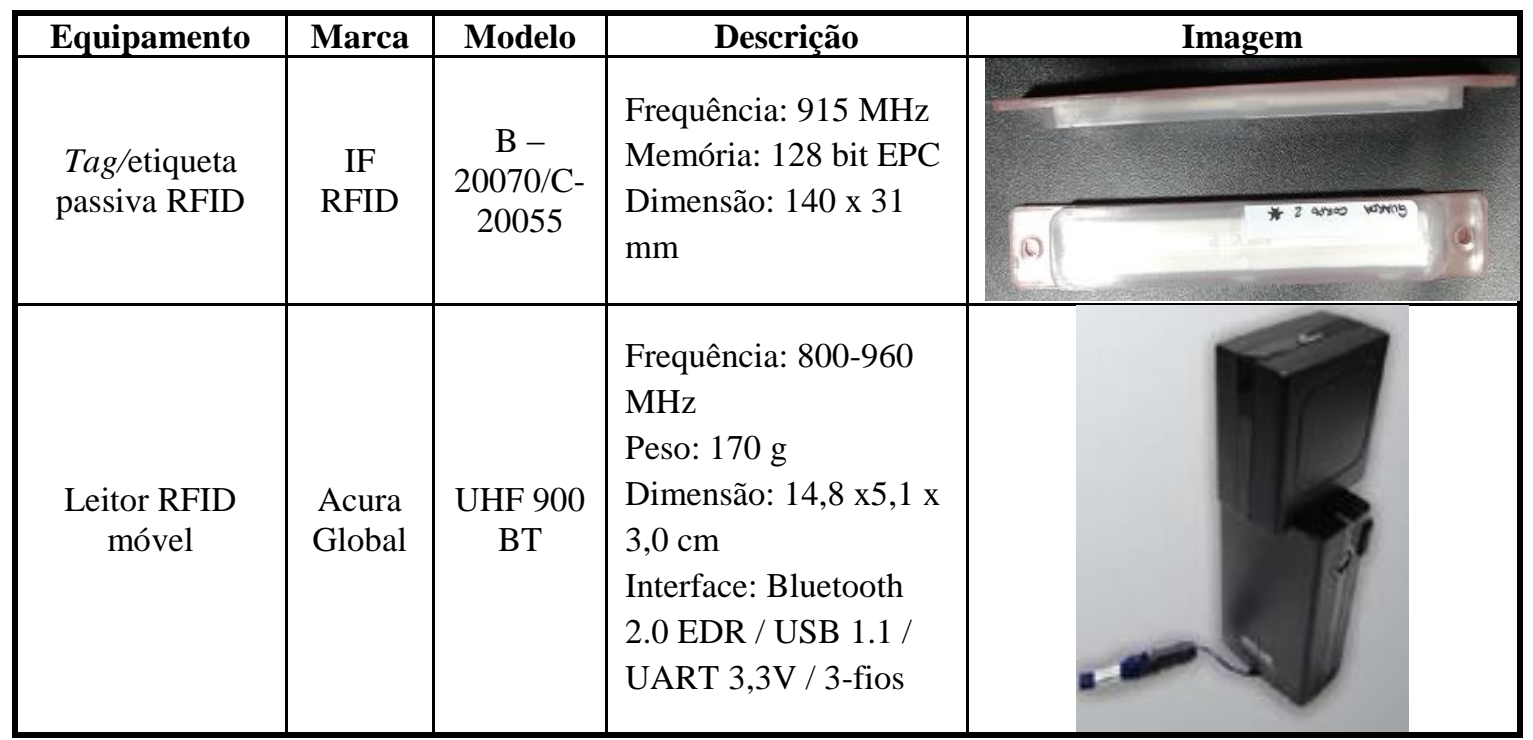


O delineamento do desenvolvimento da pesquisa é apresentado na Figura 4. Os testes foram divididos em duas etapas. A primeira foi conduzida em um ambiente laboratorial com o propósito de desenvolver, avaliar e validar os procedimentos e o funcionamento do sistema de coleta $\mathrm{e}$ processamento dos dados. A partir da formatação dos procedimentos e da validação do funcionamento do sistema foi iniciada a segunda etapa, que consistiu na realização de testes em um canteiro de obras real e em operação, reproduzindo toda a rotina de ensaio estabelecida no laboratório.

Os testes de laboratório simularam a identificação de um equipamento de segurança caracterizado pelo protótipo metálico de uma treliça de suporte para bandeja secundária fabricada em escala reduzida (2/1), dotado de uma Tag previamente cadastrada. As leituras ocorreram com a aproximação do leitor RFID sobre a Tag até que um sinal sonoro fosse emitido pelo leitor, indicando, assim, o sucesso da leitura. Essa operação foi repetida por dez vezes a fim de verificar a funcionalidade do procedimento. Os testes de validação consistiram em repetir os testes de aproximação com outras dez repetições de reconhecimento. Esperava-se com esse teste identificar variações nas leituras que pudessem invalidar o funcionamento do conjunto. Para essa etapa todos os dados obtidos durante as leituras foram anotados em uma planilha de controle de ensaio. $\mathrm{O}$ desenvolvimento do software responsável por controlar, armazenar e organizar os dados dos testes foi desenvolvido ao longo dessa etapa e utilizou as informações obtidas durante os testes para a construção de sua arquitetura e estrutura lógica.

Os testes de campo foram realizados em um canteiro de obras no $13^{\circ}$ pavimento do edifício residencial multifamiliar denominado Concept Design (Figura 5). O projeto da distribuição das bandejas e dos GcR neste andar também pode ser observado na Figura $5 b$.

Figura 4 - Etapas do desenvolvimento da pesquisa e delineamento dos ensaios

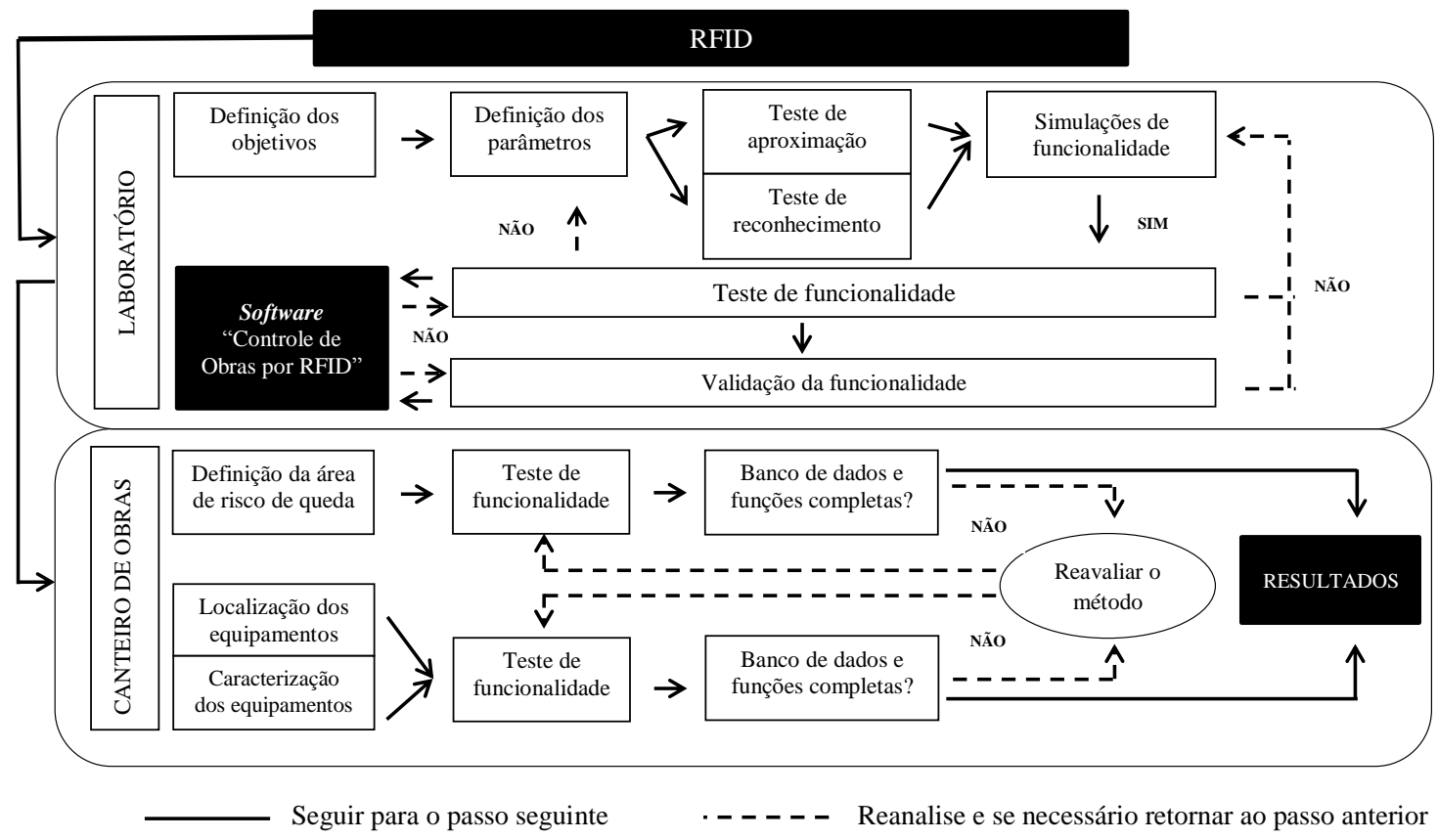

68 Oliveira, V. H. M.; Serra, S. M. B. 
Figura 5 - Vista do edifício Concept Design e do $13^{\circ}$ pavimento

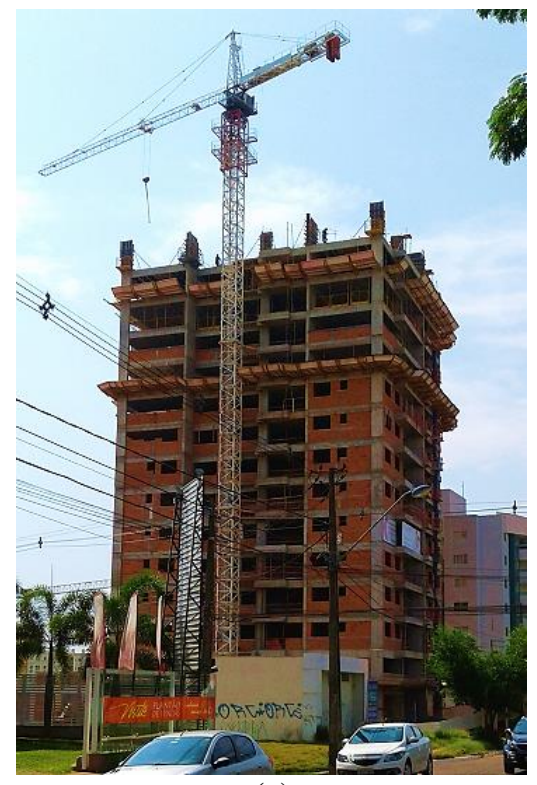

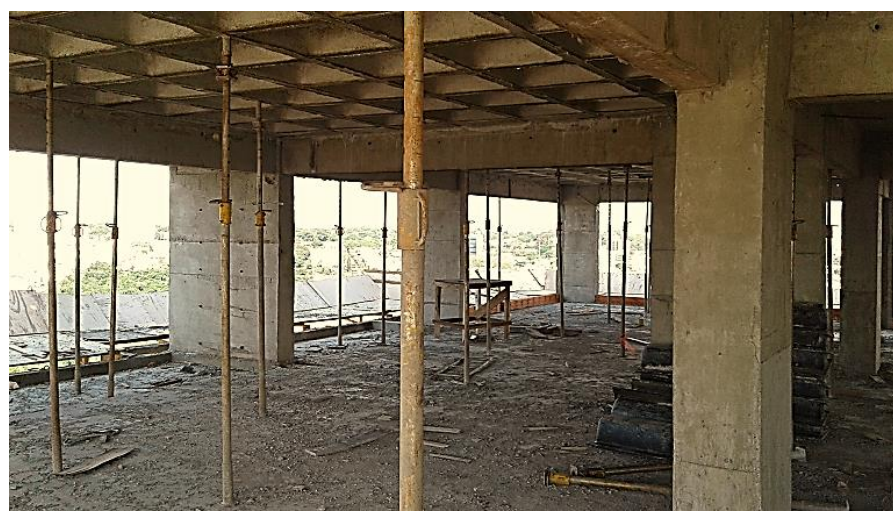

(b)

(a)

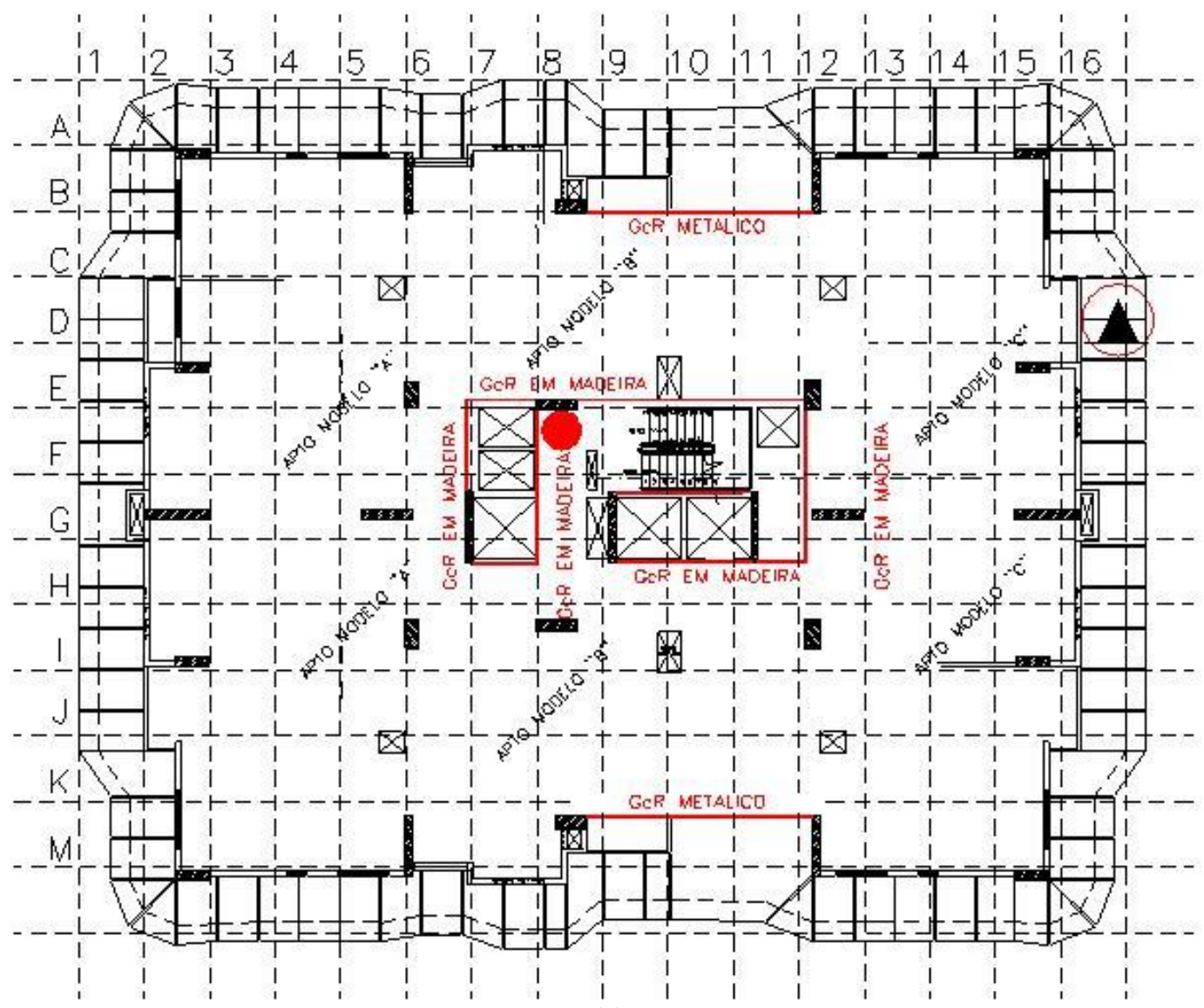

(c)

Seis etiquetas passivas foram previamente cadastradas e instaladas em equipamentos de proteção coletiva em diferentes pontos do canteiro (Figura 6). Entre os equipamentos monitorados estavam os sistemas GcR em madeira e metálico
(Figura 6). O procedimento de leitura adotado para a etapa do canteiro de obras foi igual ao da etapa de laboratório com a aproximação do leitor sobre a Tag instalada no equipamento de proteção. Entretanto, para os testes de campo os dados foram 
coletados com o apoio do software desenvolvido pelo estudo. Nesta etapa, além do êxito nas leituras, o correto funcionamento das funções do software também foi avaliado, conforme descrito pelo esquema da Figura 4.

Para avaliar o funcionamento da função de identificação dos equipamentos, as três possíveis situações foram simuladas: presente, deslocado e ausente. Para a situação "presente" a Tag foi instalada em um equipamento posicionado no local correto do cadastro. Quando a leitura apresentar a situação "deslocado", significa que a Tag foi instalada em um local diferente do local do cadastro. A situação "ausente" significa que nenhuma Tag foi instalada no equipamento analisado e que no cadastro inicial ou no anterior constava como "presente".

O procedimento de coleta de dados contou com a utilização de um tablet e de um leitor RFID móvel. Depois de realizadas as leituras, o banco de dados do tablet foi transferido para o computador que estava com o programa responsável pela compilação das informações obtidas (Figura 1).

\section{Sistema de monitoramento e controle}

\section{Detalhes da implantação do hardware e do software}

O primeiro passo na implantação do sistema de monitoramento com RFID passivo foi $o$ cadastramento de todos os equipamentos utilizados nos testes. Cada equipamento recebeu uma Tag RFID com um número de identificação exclusivo. A faixa de frequência utilizada foi de $800-960 \mathrm{Mhz}$ para Tags do modelo B-20070/C-20055, resistentes à ação de intempéries e a interferências sobre as ondas de rádio impostas por superfícies metálicas (Figura 7).

O segundo passo consistiu em estabelecer a conexão sem fio entre a Tag, o leitor e o software. Foi criado um banco de dados com as informações dos equipamentos e do local de operação (obra). O conjunto de informações que compõem o banco de dados contempla tipo de equipamento (nome), nome da obra, local da obra onde será aplicado o equipamento, marca do equipamento, material constituinte do equipamento, estado de conservação, previsão da data para a próxima revisão de manutenção e nome do responsável pelo equipamento, conforme o Quadro 2. A interface do sistema cruza as informações pré-cadastradas e vincula as informações gravadas ao conjunto de dados resultantes das leituras.

O software e o banco de dados principal ficaram hospedados em um computador matriz móvel, responsável por compilar e armazenar todas as informações obtidas com o sistema. As leituras in loco foram feitas com o apoio de um tablete, que, através de um aplicativo, também desenvolvido durante a pesquisa, se comunicou com o leitor RFID móvel e arquivou as informações obtidas com as leituras. A interface entre o tablet e o computador matriz ocorreu através da conexão dos equipamentos em uma mesma rede e em um mesmo endereço IP (Internet Protocol)

O usuário pode escolher especificamente quais dados deseja obter por meio da configuração do menu de filtragem de dados. Assim, os resultados são organizados de forma que possam ser ordenados por característica do equipamento ou por local de aplicação.

Figura 6 - Tag RFID instalada em sistemas guarda-corpo rodapé (GcR) no canteiro de obras
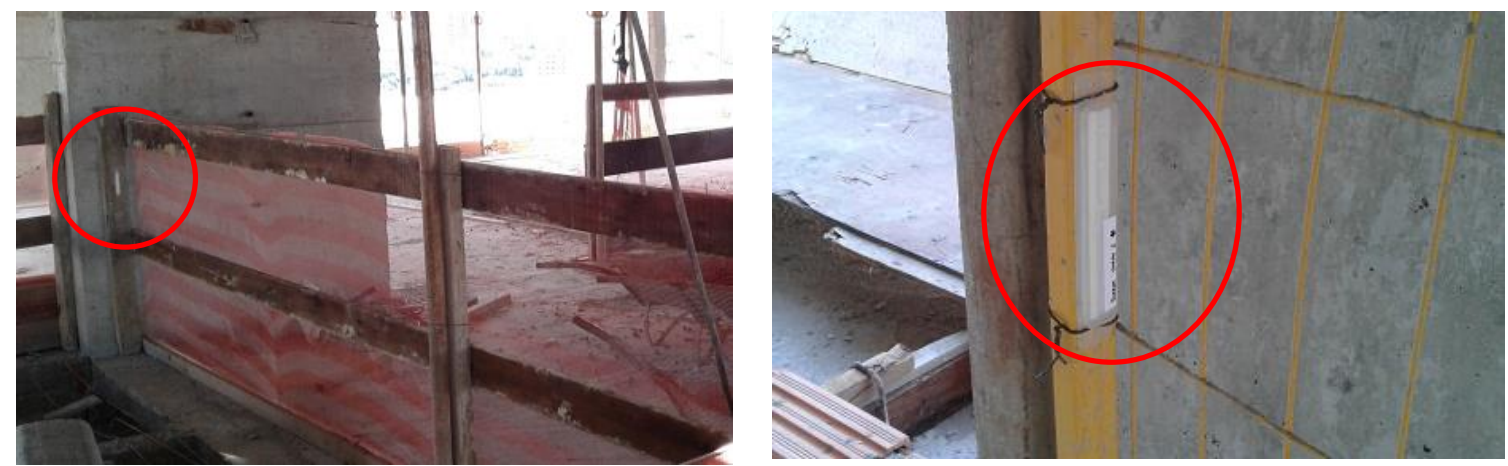

70 Oliveira, V. H. M.; Serra, S. M. B. 
Figura 7 - Instalação das Tags RFID na treliça da bandeja secundária e no sistema guarda-corpo rodapé (GCR)
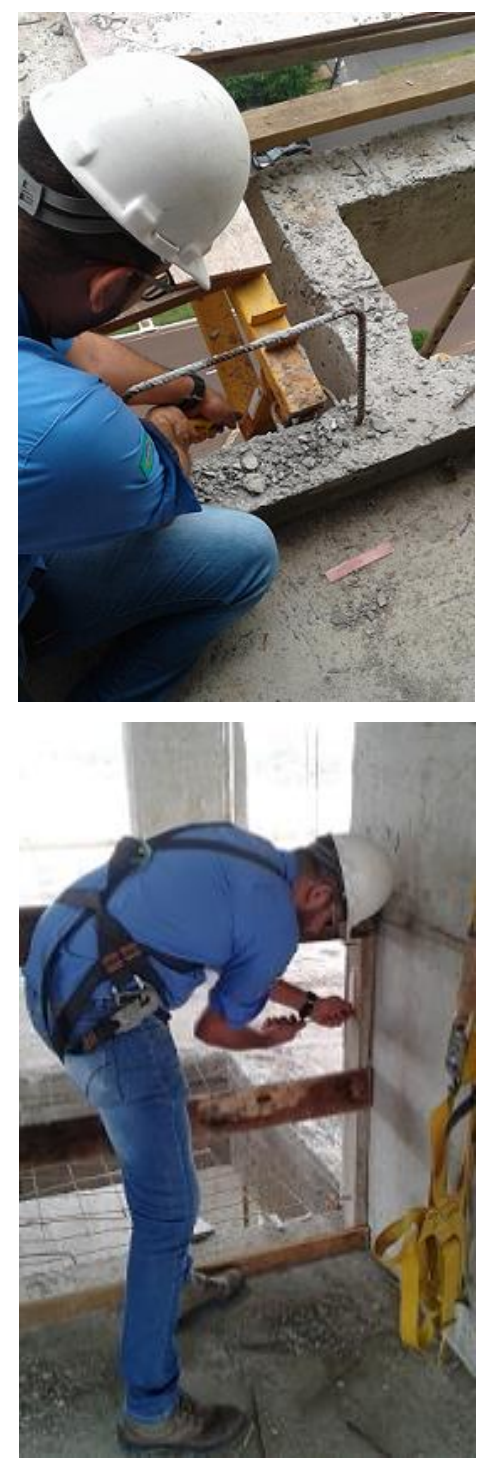
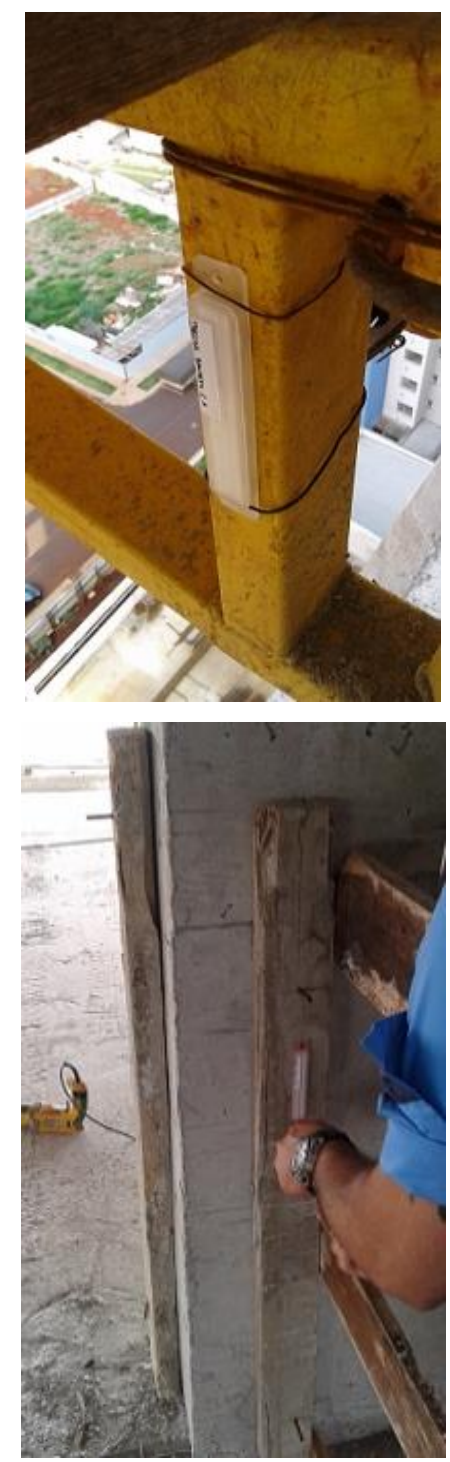

Quadro 2 - Conjunto de dados necessários para o cadastro dos equipamentos

\begin{tabular}{|l|l|}
\hline Nome: & TRELIÇA BANDEJA 2 \\
\hline Obra: & Concept Design - APTO C \\
\hline Local: & Sacada - APTO C \\
\hline Marca: & Própria \\
\hline Material: & Perfil metálico \\
\hline Estado: & Novo \\
\hline Previsão para revisão: & $18 / 12 / 2016$ \\
\hline Responsável: & Teste 1 \\
\hline
\end{tabular}

\section{Resultados}

O valor da criação de um banco de dados ficou evidente ao proporcionar que dados específicos fossem selecionados e armazenados de forma mais automatizada. Essa facilidade de obtenção dos dados, além de construir uma base histórica de informações, substituiu o registro manual realizado pelos trabalhadores de controle dos EPC. Automatizar o registro e a análise dos dados reduziu trabalho, tempo e falhas no processo. Além disso, gerou informações para a construção 
de índices de produção e de desempenho operacional para a empresa.

A ferramenta de filtragem de dados se mostrou como uma importante função do sistema computacional desenvolvido. Por meio da filtragem de dados foi possível reduzir e/ou agrupar a quantidade de informações contidas nos relatórios, eliminando, assim, redundâncias. Por exemplo, por meio da aplicação de filtros de seleção, foi possível identificar quais equipamentos estavam localizados em determinado pavimento ou, ainda, indicar quantas unidades de determinado equipamento estavam instaladas ao longo de todo o canteiro, bem como sua localização específica.

\section{Controle de obras por RFID}

O objetivo maior do desenvolvimento do sistema de monitoramento e controle foi consolidar uma ferramenta para o gerenciamento de equipamentos de segurança na construção. Para esse propósito a primeira etapa foi reconhecer e localizar os equipamentos inseridos no programa. Esta primeira etapa foi crítica, uma vez que o cadastramento dos dados era feito manualmente, passível, portanto, de falhas humanas.

Todas as interações do sistema consistiram em cruzar e comparar dados. Dessa maneira, o programa foi capaz de localizar cada elemento cadastrado, indicando se se encontrava no local correto (lido - identificado na cor verde), no local incorreto (cor laranja) ou ausente (não lido - cor vermelho), de acordo com a Figura 8. As leituras realizadas e pré-armazenadas no tablet foram transferidas ao computador matriz quando emparelhados em rede e utilizando o mesmo endereço de IP. A sincronização dos equipamentos com o banco de dados do sistema funciona continuamente, com consequente atualização de sua localização em planta.

A localização deste ponto de medição circunferência vermelha - pode ser visualizada na Figura 5b, que mostra a divisão da planta do andar em quadrantes com dimensões configuradas de dois metros (2 m x $2 \mathrm{~m})$. Essa subdivisão é flexível. Caso haja necessidade de maior ou menor precisão, basta alterar a configuração que ajusta a subdivisão dos quadrantes para mais ou para menos. Os quadrantes são nomeados com números no eixo de abscissas (x) e com letras no eixo de ordenadas (y), formando uma matriz de coordenadas (Figura 5b). Dessa forma, a localização do equipamento caracterizado pela circunferência vermelha, conforme exposto na Figura 5b, pode ser descrita, por exemplo:
(a) nome: GcR;
(b) localização: vazio elevador $-13^{\circ}$ Pavimento; e
(c) posição $7 \mathrm{~F}$.

Figura 8 - Interface de leitura para o software em um sistema operacional Android no tablet

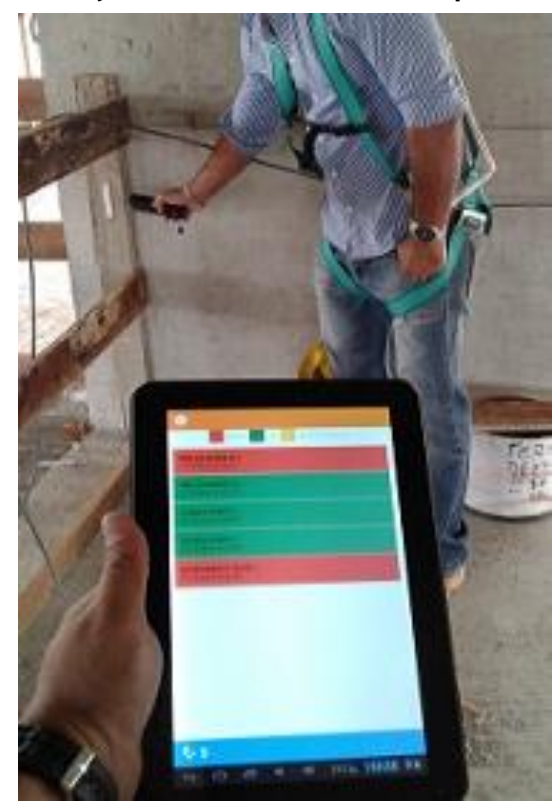

72 Oliveira, V. H. M.; Serra, S. M. B. 
Outro recurso do sistema apresenta os dados de cadastro do equipamento. Esse recurso descreve, além da localização, as características dele inseridas anteriormente. A Figura 9 exibe um exemplo do resultado gráfico proposto pelo sistema. Neste exemplo, o equipamento "Treliça Bandeja 2", legendado pelo símbolo triângulo preto e cercado pela circunferência vermelha (também localizado na Figura 5b), está sendo utilizado na obra Concept Design; está localizado na sacada do apartamento "C"; a marca do equipamento é própria, ou seja, a própria empresa o fabricou; o material de fabricação é o perfil metálico; o estado de conservação é novo; a previsão para a próxima revisão é 18/12/2016; e o responsável pelo equipamento é o funcionário "Teste 1".

Para que essa função do sistema seja utilizada, basta que o operador clique na tela do computador sobre o símbolo que representa o equipamento para que a janela de informações apareça na tela do computador. A quantidade de equipamentos que podem ser cadastrados no programa é ilimitada. Dessa maneira, o operador pode monitorar todo o canteiro de obras através de um único terminal, localizado no escritório de obra, por exemplo, sem precisar acessar efetivamente o interior do canteiro. A atualização do banco de dados deve ser realizada conforme a dinâmica operacional dos serviços, principalmente durante as etapas de desmontagem e remontagem. Cabe ao gestor da obra estabelecer os critérios de utilização conforme sua experiência e as necessidades da obra.
A Figura 10 apresenta mais um recurso do sistema. Todas as informações contidas no banco de dados do programa podem ser disponibilizadas como planilhas de relatório. Neste exemplo, o relatório descreve quais são os filtros utilizados para delimitar as informações e disponibiliza as datas de leitura, os tipos de equipamentos e todas as demais informações relevantes ao relatório solicitado.

Esta ferramenta permitiu uma visão analítica global de todas as ocorrências cumpridas pelo programa. Os relatórios são arquivos editáveis que podem ser gerados com extensões xls, txt ou pdf, permitindo que alterações ou melhorias de leiaute possam ser executadas.

Ainda como indicado na Figura 10, seis diferentes equipamentos de segurança coletiva instalados em três diferentes condições (presente, ausente, deslocado) integraram os testes. Em todas as leituras realizadas durante as simulações os resultados indicaram a correta condição do equipamento, conforme planejado no cadastro inicial proposto. Além da condição do equipamento, em $100 \%$ das leituras o sistema definiu e apresentou corretamente o conjunto de dados pertinente a cada equipamento conforme o Quadro 2 e a Figura 9. Os resultados demonstraram também que o modelo de Tag utilizado obteve êxito em seu funcionamento independentemente do material constituinte do equipamento monitorado (metal ou madeira).

Figura 9 - Resultado gráfico da identificação, descrição e localização de um equipamento instalado no canteiro

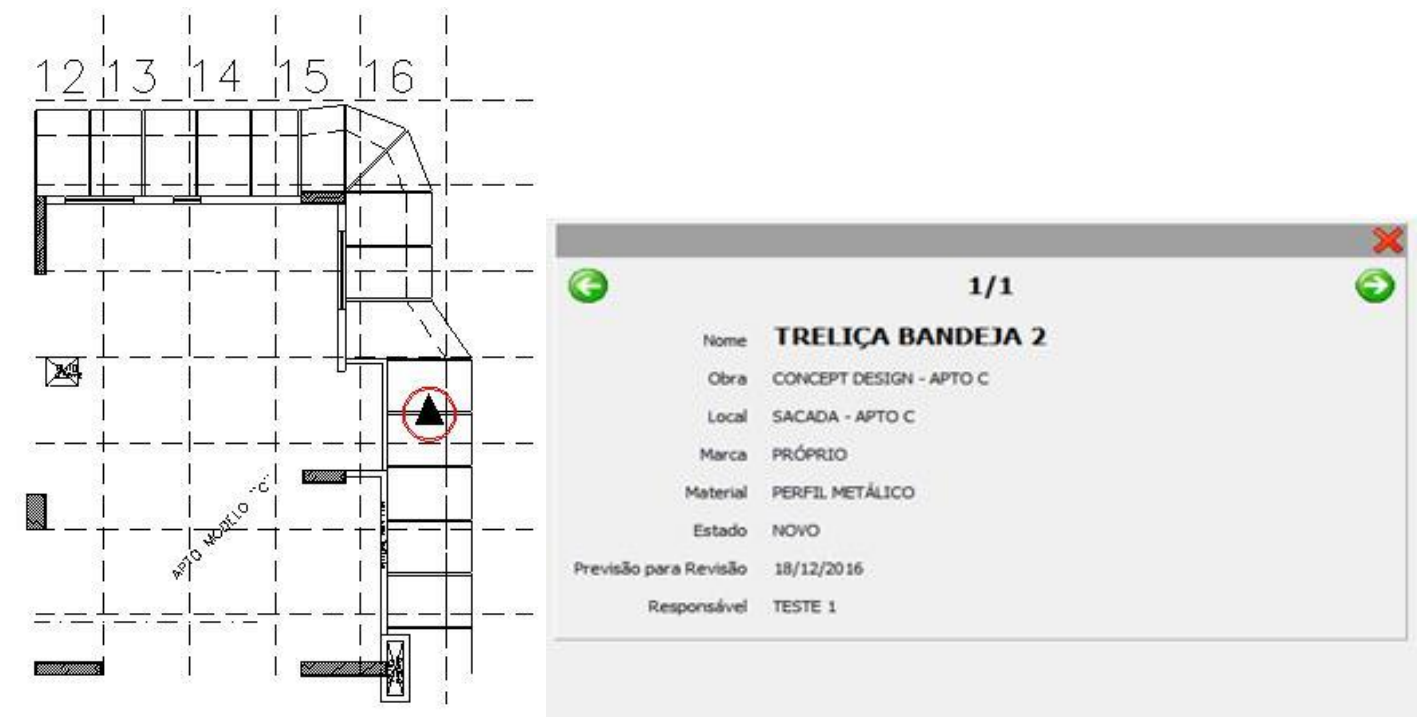


Figura 10 - Relatório gráfico de um conjunto de leituras e informações do banco de dados

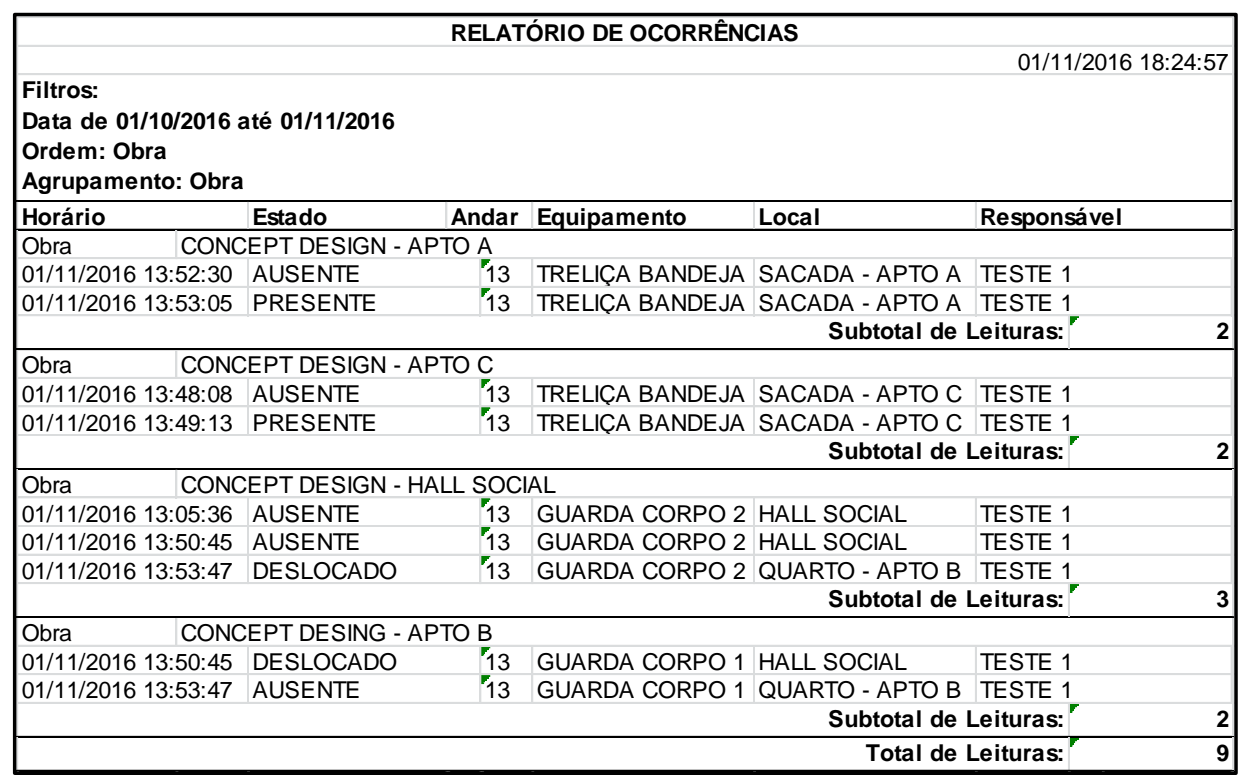

A equiparação entre os sistemas convencionais de gestão de equipamentos usualmente empregados na indústria da construção e os resultados obtidos com o Controle de Obras por RFID indica benefícios determinantes com o aperfeiçoamento no controle efetivo das peças através do monitoramento remoto. Entre as vantagens apresentadas está a possibilidade de apurar as condições e as características dos equipamentos a qualquer momento através de um terminal de controle sem que o operador se submeta aos riscos de acessar as instalações do canteiro. A construção de um histórico de operações e um banco de dados em constante atualização é outro importante avanço. Todas essas informações servem de referência para a construção de indicadores e índices da cadeia produtiva. Outros benefícios incluem a redução no tempo empregado em procedimentos tradicionalmente manuais $\mathrm{e}$ limitados, e a melhoria no acompanhamento das necessidades de manutenção e vida útil dos equipamentos, por exemplo.

\section{Interface do software}

A interface criada tornou a comunicação do operador acessível e de fácil entendimento. Procurou-se considerar durante o desenvolvimento da ferramenta as necessidades e características dos trabalhadores da construção civil, adicionando ícones aos textos. A programação visual disponibiliza as funções em forma de ícones organizados conforme a sequência de digitação. $\mathrm{O}$ software foi desenvolvido para as plataformas
Windows e Android, de forma a permitir sua hospedagem em computadores que utilizam o sistema operacional Windows (Figura 11a) e tablets ou smartphones que utilizam o sistema operacional Android (Figura 11b).

As dificuldades e o grande número de variáveis envolvidas no desenvolvimento de um sistema de monitoramento e controle que utiliza a tecnologia RFID foram superados com os ensaios de campo e proporcionaram obter um recurso de fácil operação. Um dos desafios na implantação das TIC nos canteiros é tornar as ferramentas acessíveis aos trabalhadores. Acredita-se que essa barreira foi superada pela simplicidade operacional desse sistema. A automação no registro e a coleta de dados com a redução nas etapas do processo geraram consequente redução de tempo, custo e erros, sem criar novas dificuldades para um ambiente de trabalho que já se mostra complexo, como os canteiros de obra.

\section{Considerações finais}

A tecnologia RFID tem sido o conteúdo de uma série de pesquisas voltadas à indústria da construção. Esta pesquisa apresentou resultados da aplicação RFID com a finalidade específica de constituir um sistema destinado ao monitoramento remoto de equipamentos de segurança. Ao longo do trabalho, descreveram-se a estrutura e o funcionamento de um método de gestão direcionado para a indústria da construção. 
Figura 11 - Interface do software para (a) Windows e (b) Android

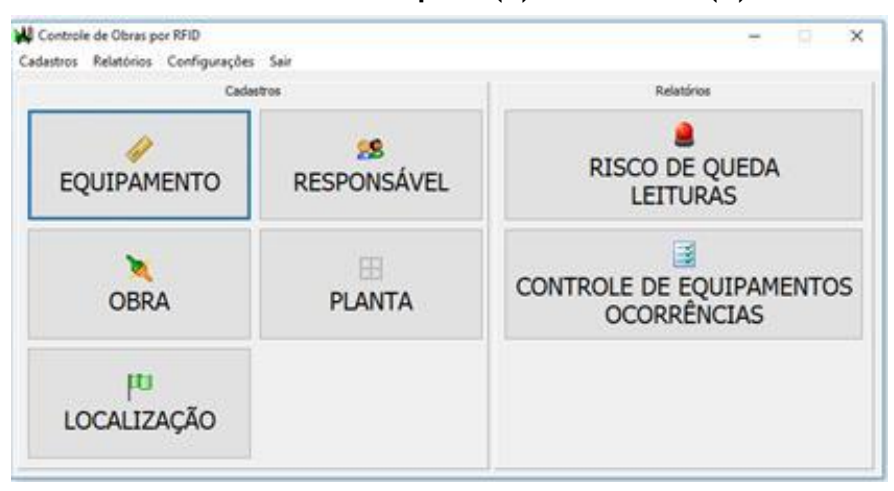

(a)

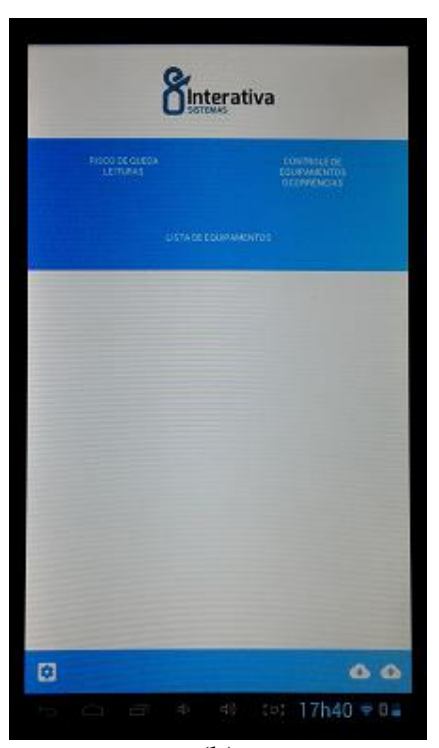

(b)
Os testes que determinaram a funcionalidade do sistema e o desenvolvimento do software foram conduzidos paralelamente. $\mathrm{O}$ ambiente que hospedou os testes no canteiro apresentava uma série de interferências, como elementos de concreto, perfis metálicos e painéis de madeira. Mesmo diante desses obstáculos, comuns ao dia a dia do canteiro, o conjunto formado pelos equipamentos RFID e o software obteve êxito nas leituras realizadas, com a consequente identificação e localização dos equipamentos monitorados. A utilização de Tags com atributos específicos, protegidas contra a ação e a interferência de elementos metálicos e intempéries, foi fundamental para alcançar os resultados obtidos.

Em geral, na indústria da construção, o controle e a gestão de equipamentos de segurança é feito manualmente em papel. $\mathrm{O}$ processo de identificar a funcionalidade, a viabilidade e a acessibilidade de um sistema utilizando a TIC em substituição aos métodos usuais é uma contribuição para a evolução da incorporação de novos instrumentos no canteiro. Além disso, os resultados produziram uma ferramenta com funções que alteram por completo a maneira de administrar a gestão dos equipamentos. Inovações como o monitoramento em tempo real, o monitoramento remoto sem a necessidade de se submeter aos riscos de segurança existentes ao se locomover pelo canteiro, o controle de estoque promovido pela necessidade do cadastro de todos os equipamentos empregados no canteiro e sua constante atualização, a redução do risco de acidentes devido ao controle do período de manutenção dos equipamentos, a criação de um banco de dados e a construção de um histórico de utilização são apenas alguns dos benefícios e contribuições resultantes desta pesquisa.

A simplicidade na operação do sistema foi um propósito perseguido ao longo de seu desenvolvimento. Ter conseguido atingir essa condição tornou a ferramenta atrativa, em vez de complexa e burocrática. Espera-se com isso estimular os trabalhadores a aceitá-la. Nesse sentido, a concepção da interface com o sistema operacional Android trouxe uma grande contribuição: o uso do sistema através de smartphones ou tablets aproxima a tecnologia dos trabalhadores, pois esses são equipamentos com que eles estão habituados e que fazem parte de sua rotina, o que humaniza a adoção da tecnologia.

Os resultados das leituras e do banco de dados organizados em forma de relatórios e planilhas dotadas de filtros para a escolha das informações a serem transmitidas enriqueceram a apresentação das informações. Além disso, os resultados gráficos em forma de plantas com a identificação dos equipamentos nelas presentes simplificaram e dinamizaram a forma com que os operadores e os gestores tiveram acesso às informações geradas pelo sistema.

A abrangência da pesquisa limita-se a propor o desenvolvimento do sistema de monitoramento e controle de EPC na construção civil utilizando a tecnologia RFID. As ações abordadas pela investigação abrangem a verificação da funcionalidade da tecnologia RFID para atingir os objetivos da pesquisa, a viabilidade técnica na implantação do sistema e o desenvolvimento de um programa computacional responsável por gerir 
e compilar os dados obtidos ao longo da operação do sistema.

As contribuições para a continuidade de novas pesquisas são abrangentes. Um exemplo direto para futuras aplicações do sistema seria ampliar o monitoramento para outros tipos de equipamentos e ferramentas, como furadeiras, serras circulares, parafusadeiras, etc., usualmente presentes nos canteiros de obras.

\section{Referências}

BRASIL. Ministério da Previdência Social. Anuário Estatístico de Acidentes do Trabalho. 2015a. Disponível em: <www.previdencia.gov.br/dados-abertos/dadosabertos-sst/>. Acesso em: 4 jun. 2017.

BRASIL. Ministério do Trabalho e Emprego. Norma Regulamentadora 18 (NR-18): condições e meio ambiente de trabalho na indústria da construção, 2015b.

COSTIN, A.; PRADHANANGA, N.; TEIZER, J. Leveraging Passive RFID Technology for Construction Resource Field Mobility and Status Monitoring in a High-Rise Renovation Project. Automation in Construction, v. 7, n. 24, p. 1-15, 2012.

DEMIRALP, G.; GUVEN, G.; ERGEN, E. Analyzing the Benefits of RFID Technology for Cost Sharing in Construction Supply Chains: a case study on prefabricated precast components. Automation in Construction, v. 7, n. 24, p. 120129, 2012.

DOMDOUZIS, K.; KUMAR, B.; ANUMBA, C. Radio-Frequency Identification (RFID) Applications: a brief introduction. Advanced Engineering Informatics, v. 21, n. 4, p. 350-355, 2007.

\section{FINKENZELLER, K. RFID Handbook:}

fundamentals and applications in contactless smart cards, radio frequency identification and nearfield. Londres: Wiley, 2010.

FONTELLES, M. J. et al. Metodologia da Pesquisa Científica: diretrizes para a elaboração de um protocolo de pesquisa. Núcleo de Bioestatística Aplicado à Pesquisa da Universidade da Amazônia - Unama. Amazonas, 2009.

GERHARDT, T. E.; SILVEIRA, D. T. Métodos de Pesquisa. Porto Alegre: Ed. da UFRGS, 2009.

GIRETTI, A. et al. Design and First Development of an Automated Real-Time Safety Management System for Construction Sites. Journal of Civil Engineering and Management, v. 15, n. 4, p. 325-336, 2009.
HEVNER, A. R. et al. Design Science in Information Systems Research. Mis Quarterly, v. 28, p. 75-105, 2004.

\section{HOLLNAGEL, E. Barriers and Accident} Prevention. Ashgate, 2004.

KAUARK, F. S.; MANHÃES, F. C.; MEDEIROS, C. H. Metodologia da Pesquisa: um guia prático. Itabuna: Via Litterarum, 2010.

LIESHOUT, M. C. et al. RFID Technologies: Emerging Issues, Challenges and Policy Options. Institute for Prospective Technological Studies. Joint Research Centre. European Comission, 2007.

MAGHIROS, J.; ROTTER, P.; LIESHOUT, M. RFID Technologies: emerging issues, challenges and policy options. Institute for Prospective Technological Studies. Joint Research Centre. European Comission, 2007.

MEHRJERDI, Y. Z. RFID-Enabled Systems: a brief review. Emerald Group Publishing Limited, Yazd, v. 28, n. 3, p. 235-245, 2008.

REN, Z.; ANUMBA, C. J.; TAH, J. RFIDFacilitated Construction Materials Management (RFID-CMM): a case study of water-supply project. Advanced Engineering Informatics, v. 25, p. 198-207, 2011.

RIAZ, Z.; EDWARDS, D. J.; THORPE, A.

SightSafety: a hybrid information and communication technology system for reducing vehicle/pedestrian collisions. Automation in Construction, v. 15, p. 719-728, 2006.

RFID JOURNAL BRASIL. Solução Controla o Uso de EPI's no Setor de Energia. Abr. 2015. Disponível em: <http://brasil.rfidjournal.com/noticias/vision?1305 7/\#back-from-modal>. Acesso em: 9 abr. 2016.

SANGREMAN, A.; CAMANHO, T. RFID: prós e contras. Trabalho da disciplina Rede de Computadores. Escola Politécnica da Universidade Federal do Rio de Janeiro. 2007. Disponível em: <http://www.gta.ufrj.br/grad/07_1/rfid/RFID_arqui vos/prosecontras.htm>. Acesso em: 5 jun. 2017.

SONG, J. et al. Locating Materials on Construction Site Using Proximity Techniques. In: CONSTRUCTION RESEARCH CONGRESS, San Diego, 2005. Proceedings... San Diego, 2005.

THOMAZ, E. Tecnologia, Gerenciamento e Qualidade na Construção. São Paulo: Pini, 2001.

VAN AKEN, J. E. Research Based on the Paradigm of the Design Sciences: the quest forfield-tested and grounded technological rules. Journal of Management Studies, v. 41, p. 219246, 2004. 
WU, W. et al. An Integrated Information Management Model for Proactive Prevention of Struck-by-Falling-Object Accidents on Construction sites. Automation in Construction, v. 34, p. 67-74, 2013.

ZHEKUN, L.; GADH, R.; PRABHU, B. S.

Applications of RFID Technology and Smart Parts in Manufacturing. In: DESIGN ENGINEERING

TECHNICAL CONFERENCES AND

COMPUTERS AND INFORMATION IN

ENGINEERING, 2004, Proceedings... Salt Lake

City, 2004.

\section{Agradecimento}

Ao projeto de pesquisa Tecnologias para Canteiro de Obras Sustentável de Habitações de Interesse Social (Cantechis), amparado pela Financiadora de Estudos e Projetos (Finep), que apoiou integralmente este trabalho.

\section{Revista Ambiente Construído}

Associação Nacional de Tecnologia do Ambiente Construído

Av. Osvaldo Aranha, $99-3^{\circ}$ andar, Centro

Porto Alegre - RS - Brasil

CEP $90035-190$

Telefone: +55 (51) 3308-4084

Fax: +55 (51) 3308-4054

www.seer.ufrgs.br/ambienteconstruido

E-mail: ambienteconstruido@ufrgs.br 